\title{
ARTICLES
}

\section{INTELLECTUAL FREEDOM \& CENSORSHIP: A TEACHING CHALLENGE}

\author{
by Dr. Ann Curry
}

The concepts of intellectual freedom and censorship are key to the practice of librarianship, and introducing students to these concepts should be an important part of any library and information science program curriculum. Teaching this topic is often problematic, however, because personal values and beliefs are involved and because many related issues continue to be unresolved not only in society but by practitioners themselves. In the experience of this teacher, a combination of readings (both current and historical), class discussions, and small group casestudy analyses has proved to be most effective in introducing the topic since the concepts themselves are exceedingly complex and require a variety of teaching approaches.

In the 1990s, issues such as multiculturalism, political correctness, racism, and the impact of pormography and violence portrayed in the media have made the relationship between intellectual freedom and the library profession a subject of continuing debate for practising librarians and very perplexing for students. This article explains briefly some of the themes and arguments used for instruction and details the results of three intellectual freedom related questions asked of 60 directors of large public libraries in Canada and the U.K. as part of a larger research project (Curry, 1993). The opinions of these directors have formed the basis of instructional case studies and have been drawn upon frequently to show students not only the various sides of intellectual freedom issues but also the conflicting opinions within the library profession. Although the research results are limited to two countries, the conclusions have international application.

When teaching, one must concentrate on the laws, issues and professional philosophies of one's own country, but international publishing, satellite television broadcasts, and the Internet have given a global dimension to many intellectual freedom issues such as Salman Rushdie's Satanic Verses. As well, recent trade agreements and promising job markets have prompted some Canadian library science graduates to seek employment in the U.S. and the U.K. For these reasons primarily, a more international focus is appropriate when introducing intellectual freedom and censorship to students.

\section{BACKGROUND READING}

John Stuart Mill's On Liberty (1974) and John Milton's Areopagitica (1951) make arduous reading for many students, but study guides and class discussions linking the authors' philosophies with library issues usually lead students to appreciate these key historical texts. They continue to be quoted in 1990s censorship debates and lend historical context to current intellectual freedom statements, making worthwhile the students' efforts interpreting this prose of previous centuries. As further historical background, the accomplishments of Lenin's spouse, librarian Nadezhda Skrupskaia, can be introduced to acquaint students with the opposing viewpoint regarding govemment involvement in control of information.

Current readings assigned to students are best selected with regard to issues of topical interest, but the works of Hauptman (1988), and Swan (1989) are recommended. In addition, Woodward's article on ethics (1990) is particularly effective as an introduction to the methods used by society (including the students themselves) when deciding ethical issues such the availability of controversial information.

\section{LIBRARY ASSOCIATION CODES}

Relevant documents from professional library associations should also be included in an instructional package on censorship and intellectual freedom. These documents may be codes of ethics, freedom to read statements, library bills of rights, or general policies on intellectual freedom, depending on the association. Those from the Canadian, British, and American associations are particularly useful for background reading or examination.

The Canadian Library Association (CLA) has both a Statement on Intellectual Freedom and a Code of Ethics which guide the conduct of its members. The Statement notes that Canadians have the fundamental right: 
...to have access to all expressions of knowledge, creativity and intellectual activity, and to express their thoughts publicly.

It further states that:

It is the responsibility of libraries to guarantee and facilitate access to all expressions of knowledge and intellectual activity, including those which some elements of society may consider to be unconventional, unpopular or unacceptable. To this end, libraries shall acquire and make available the widest variety of materials. (CLA, 1985)

The Code of Ethics, which is currently under review (Ellis, 1994), states that librarians have a responsibility to uphold the Intellectual Freedom Statement and adds further responsibilities pertaining to high standards of service and the need to "protect the privacy and dignity of library users and staff."

Classroom discussion of documents will alert students to the professional beliefs agreed upon by association members, but these discussions must include the federal and provincial/ state laws which affect professional practice. For example, the Canadian Charter of Rights and Freedoms (effective 1984), states that freedom of thought, belief, opinion and expression are: ...subject only to such reasonable limits prescribed by law as can be demonstrably justified in a free and democratic society. (Constitution Act, 1982)

Recent court cases dealing with pornographic adult videos ( $R$. v. Butler) and paintings depicting children in sexual activity ("Child-porn," 1993) are further defining what the Canadian courts consider to be "reasonable limits." Students should also be introduced to federal and provincial/state freedom of information legislation because these laws further define what information may be restricted by government and what privacy rights may be exercised by individuals.

In the U.K., the Library Association's (LA) 1983 Code of Professional Conduct (LA, 1987, p. 120) and the Code's guidance notes (LA, 1986) are the most influential association documents pertaining to intellectual freedom. Section $\mathrm{f}$ of the Code states that:

In places to which the public has right of access, save where the flow of information must be restricted by reason of confidentiality, members have an obligation to facilitate the flow of information and ideas and to protect and promote the rights of every individual to have free and equal access to sources of information without discrimination and within the limits of the law.

Section $\mathrm{g}$ is equally important:

Members shall not knowingly promote material the prime purpose of which is to encourage discrimination on the grounds of race, colour, creed, gender or sexual orientation. It shall not be regarded as promoting such material to divulge it for the purpose of studying the subject of that discrimination.
The Code is intended as "an indication of the standards of behaviour expected of a member" (LA, 1986) and although voluntary adherence is stated to be the norm, disciplinary action such as suspension or expulsion from the Association is stated in section $3 a$ as the possible result of putting personal interests ahead of professional interests:

The essential principle which lies behind the Code is that the professional librarian's prime duty is to facilitate access to materials and information in order to meet the requirement of the client, irrespective of the librarian's personal interests and views on the content of the material and the client's requirement. (LA, 1986)

Of the three associations, the American Library Association (ALA) has had the most extensive and lengthy involvement in the formulation of intellectual freedom codes. The original ALA Bill of Rights adopted in 1939 has undergone many revisions, but its focus has remained constant and it continues to anchor ALA policies. The Bill currently states that libraries have a duty to "challenge censorship in fulfillment of their responsibility to provide information and enlightenment." It states more specifically that "libraries should provide materials and information presenting all points of view on current and historical issues," and that "materials should not be proscribed or removed because of partisan or doctrinal disapproval" (ALA, 1992, p. 3). The ALA Intellectual Freedom Manual is the most comprehensive resource document on this subject for students: its detailed and up-to-date interpretations are relied upon extensively not only in the U.S. but also influence librarians in Canada and the U.K. (Curry, 1993, pp. 439, 445). Topics in the Manual of particular importance for teaching purposes (and often ones generating considerable class discussion) are children's access to material, labelling, policies on meeting rooms and display areas, and the actions recommended to prepare for censorship challenges. It should be noted that ALA has a Code of Professional Ethics which is similar in intent and wording to those of CLA and the LA, and that this Code is currently being revised.

\section{OPINIONS OF PUBLIC LIBRARY DIRECTORS: RESEARCH RESULTS}

A crucial component in learning about intellectual freedom and censorship is recognizing that librarians' personal beliefs may influence and/or conflict with professional beliefs. To present this phenomenon, classroom instructional material has been formulated from sections of a larger study (Curry, 1993), whose primary purpose was to determine Canadian and British public library directors' attitudes towards intellectual freedom policies and procedures and to explore the professional experiences which may have influenced formation of those attitudes. Sixty directors (30 Canadian, 30 British) who manage library systems serving more than 150,000 were personally interviewed during 1991. Professional experiences were not 
considered in isolation, however. Personal beliefs were also investigated so that so a more complete picture of directors' attitudes could be achieved. Precedence for this examination of librarians' personal opinions exists in the work of England (1974) and Busha (1972), and more recent examination was felt to be warranted. The results of three questions from the larger study are presented here to show the building material from which the case studies were constructed. Due to the focus of the original study, a comparison between Canada and Britain, the source materials are primarily from those two countries. The issues and directors' opinions, however, can be considered in a broader context.

The interviewer constructed nine general statements conceming the application of intellectual freedom in current societal controversies, some from issues appearing in the general British or Canadian media, others stemming from those discussed in library journals. They were intended to be current, relevant in both countries involved, and connected with possible management decisions made by library directors. The issues covered topics such as media conglomerates, pormography, homosexuality, multiculturalism, information technology, protection from offensive material, and freedom of information. The three issues presented here concern the right not to be offended, the right of all ideas to be heard, and the possible conflict between intellectual freedom and multiculturalism.

Direct quotes from respondents are displayed in italics, with (Can.) Canadian or (U.K.) United Kingdom indicating nationality.

\section{The right not be be offended}

Sexually explicit material is often protested against, whether in public libraries or in the general marketplace, because it causes offence. In Britain, women belonging to the group Campaign Against Pornography urged store owners not to stock pornographic magazines so women would not be offended by their presence. It was reported that some stores did so and advertised their establishments as "offence-free" (Bunting, 1990, p. 8).

In Canada, the Ontario Human Rights Commission was petitioned to order the removal of soft pornography magazines such as Playboy and Penthouse from convenience stores because the women complainants are uncomfortable in the "hostile environment" they create (Fennell, 1993, p. 14). Their petition asserts that the right of women not to be offended must take precedence over individual rights to accessmaterial. An editorial in The Globe and Mail, Canada's national newspaper, counters that this argument makes the rights of the allegedly harmed individuals unassailable (Right to offend, 1993, p. A14), contrary to the usual provisions of human rights legislation which attempt a balancing of competing rights. The restraints called for in the petition are described as "dangerous...censorship of unprecedented breadth: censorship of rudeness." The editorial concludes that "As the censored (and ultimately murdered) Soviet-Jewish writer Isaac Babel said in 1934, the right to write badly is no small thing; in our context, we might say the right to give offence must not be undervalued."

When the 60 directors in the study were asked whether an individual should have an absolute right to protection from material which he or she finds personally offensive, 19 of 30 British $(63 \%)$ and 23 of 30 Canadian directors (77\%) disagreed or strongly disagreed with such a right (graph 1).

Considerable similarity exists in the British and Canadian reasons for disagreeing. Most believe that the individual has the primary responsibility to protect his/her own mind, a responsibility that society and the library should not assume.

People can find their own protection. They can not look at it, turn it off, shut the book...but don't burn it though! (U.K.)

They categorized the idea of protection as "insulting", and said that the philosophy expressed therein "reduced people to children." By implication, they question how much harm can result from the momentary encounter with offensive material needed for its evaluation.

People shouldn't be protected because life is not like that. Life is hard, and hard decisions have to be made. Adults should know something about paths not taken. (U.K.)

Protecting people from offense was labelled as "undemocratic," particularly by those who strongly disagreed. A British director said the idea was "abhorrent to the democratic process" because people must have the right to choose, while a Canadian director said that the idea "flies in the face of democratic principles," considered a great responsibility in themselves. Practical questions such as how to identify all offensive material and "who censors the censors?" concermed many.

The smaller number of directors who would give this right think they should not have to see things they do not wish to see. The Canadians of this opinion referred exclusively to the right not to be "surprised" by abhorrent images or words: "aggressively confronted with offense," in the words of one. They expect society (and the public library) to assume some responsibility for prevention of this confrontation. In contrast, only one of the eleven British directors mentioned this element of unexpected offense. The British concentrated on:

1) the extreme offensiveness of images in today's society, $(n=7)$

2) the degrees of protection which are acceptable, $(n=6)$ and/or

3) the need for ethnic minority groups to be protected from experiencing offense. $(n=4)$

The increasing explicitness of objectionable images over the years, they said, had finally resulted in some images which are extremely offensive. Those who differentiated degrees of protection said that "cosseting" or "mollycoddling" is not needed but that people have a right to be "sheltered" from indecent or shockingly offensive material.

I would like it to be so. I don't know how, but I agree that somehow that right [to protection] should be there. (U.K.) 
A relationship could be discerned between responses of the Canadian directors and their length of experience. All seven who agreed that people should have the right to be protected from offensive material had 10 or fewer years of experience in director level positions. In contrast, seven of the eight who strongly disagreed had 16 or more years of director-level experience. Greater managerial experience in libraries apparently leads Canadian directors to believe that protection of the public in this area is either not needed or not practicable. The different ages of the directors appeared to have no bearing, nor was either factor an evident determinant of the stances of the British.

\section{The right of all ideas to be heard}

Canadian, American, and British, societies are concemed with defining limits, if any, to the freedom to disseminate information. In 1990, the public prosecutor of the City of Cincinnati charged the Contemporary Arts Center andits director for publicly showing obscene photographs in an exhibition of Mapplethorpe photographs. Some gallery visitors and others who had never seen the exhibit complained that many of the photographs are repulsive; others defended them as the works of a richly talented photographer. The gallery director and board were eventually cleared of obscenity charges, but news of the protests against homoerotic images and naked children became international news (Vincent, 1990, p. A13). Lyrics of rock songs have also recently prompted obscenity charges in several jurisdictions. Parents have attempted to ban particular songs as being extremely repulsive because of the portrayal of violence against women and the police. Public prosecutors in both Canada and the United States charged the rock group 2 Live Crew with obscenity because of the vulgar, disgusting, and de-humanizing nature of its lyrics.

Even some authors express concern about the proliferation of repulsive ideas in the marketplace. British author A.S. Byatt is irritated that "... the artistic and intellectual Left are so glibly sure that ... human freedom requires the unconstrained availability of dirt and damage. Free speech is not a value that overrides all others in all situations" (Byatt, 1988, p. 159). The editor of London's underground magazine $O Z$ in the 1960s, Richard Neville, is now worried about the moral repercussions of sadistic videos and novels. He uses an environmental pollution analogy to make his point: "For as surely as toxic residues kill the fish and the fowl, so the sludge of mean-spirited filmmakers and writers kill our spirit. It is renewal that is needed now, honour and optimism, not the sordid excesses of artists talented in merely shocking us. We must regain our sense of discrimination" (Neville, 1990, p. 102). British writerSusan Mendus also voices strong concerns, saying that "the right to further argument by speaking freely is not identical with the right to abuse," and supporting restriction of repulsive material which may cause outrage and offence (Mendus, 1990, p. 11).

When directors responded to the statement "All ideas, no matter how repulsive, have a right to be heard" 22 British (73\%) and 24 Canadian directors (80\%) agreed or strongly agreed (graph 2). Despite this degree of agreement and the small number of neutral responses, the subsequent comments show that agreement in practice lags far behind that in principle. In the entire interview process (involving 50 questions), no agreement or disagreement was qualified so strongly by conditions. The most notable ones are:

1) ideas cannot be imposed on people $(n=39)$,

2) the context must be appropriate $(n=27)$,

3 ) those espousing repulsive ideas must accept opposition ( $n=15)$.

The first condition may be described as "not granting someone the right to be listened to." The right of an opinionated person to a forim to express repulsive ideas persistently can, in the view of these directors, be distinguished from the right of the ideas to exist in the abstract and anyone in the way of the communication must have the option of not seeing/listening and of walking away from whoever espouses those ideas.

They [ideas] have a right to be heard...but I do not agree that they have a right to be juxtaposed in people's lives. You must not say to a person that they have no right to express the opinion that they hold, that is dangerous. [But] I think there is a limitation to how often that somebody who's got a view that is clearly unpalatable to the majority of society has the opportunity and frequency to express it in all its forms. It's one thing for me to say that there is nothing the matter with murder, but I don't expect that idea or that person propagating it to keep cropping up through my life or in the society I live in. I can understand people objecting to the views of a very small minority popping up wheresoever they look or in whatever guise... I think society has a right to limit the ways in which those unpalatable views are being thrust at us. (U.K.)

Many directors consider that nobody should have the absolute right to "propagandize" repulsive ideas in the mass media or in any other locale or context which would constitute an unwanted intrusion for most people. They stressed that those promoting ideas abhorrent to the general public have no right to command attention, and that neither society in general nor the public library in particular is obligated to provide a public forum for them.

Directors attach considerable importance to the context in which repulsive ideas are disseminated: where the ideas are distributed and how they are expressed. They spoke of inappropriate communication methods and unsuitable environments and gave examples such as shouting in a public square; distributing these ideas in a schoolyard; promoting them on public library premises, such as meeting rooms and display spaces; and interviews on mass media, particularly radio and television.

Intellectual freedom requires responsibility, and how and where dreadful ideas are heard is part of that responsibility. (U.K.) 
It was mainly British directors who noted the necessity of those espousing repulsive ideas to accept opposition. They feel that members of a democratic society have a right (some considered it a responsibility) to contest abhorrent ideas and speakers have a concomitant responsibility to tolerate this torrent of counter opinion.

Ideas stand or fall by the quality of the challenges that confront them through open discussion, so the right to be heard must be coupled with the responsibility to be challenged. (U.K.)

Most of those directors who disagreed that all ideas have a right to be heard believe some are so abhorrent that they do not have the right to be included in a civilized society no matter what conditions might be in place. These ideas were often described as "beyond the pale" or "beyond the edge." Directors in this group expressed the same view as Canadian library school professor S.D. Neill $(1988$, p. 36$)$ that society has the right to "draw a line somewhere" with some ideas so they can be "denied the light of day." When asked for an example of an idea which did not have the right to be heard, most Canadian and British directors cited ideas advocating or fostering hatred of a particular racial group.

In general, a director's answers depended on whether or not he/she accepts the philosophy attributed to Voltaire - "I disapprove of what you say, but I will defend to the death your right to say it." Assenting directors see this as a democratic principle and believe absolute suppression of repulsive ideas would engender more harm than good.

If we don't know the repulsive, we don't know the beautiful. (Can.)

Suppressing the idea tends to reinforce the idea that

it has some value or some substance. (U.K.)

Despite this faith in the basic principle, $90 \%$ of directors added conditions to their approval: repulsive ideas may have the right to be promoted in society, but the right to promote them comes with restraints. In comparison, directors who disagreed with the interview statement believe some ideas should not be available under any circumstances and that a "civilized society" has the responsibility to deny those ideas the right to be heard.

\section{Intellectual Freedom and Multicultural Harmony}

Britain, Canada, and the U.S. have become much more multicultural over the past thinty years, largely through increased immigration of visible minorities. These immigrants have brought a cultural diversity and richness but absorption of the disparate groups into the social fabric has provoked racial tension in all three countries. This last interview statement explores whether the practical problems of cultural coexistence have had an impact on directors' application of intellectual freedom principles.

As first elucidated in Canada by Pierre Trudeau in 1971, multiculturalism was an official federal government policy designed to make Canadian society stronger by recognizing, preserving, and highlighting the diversity of backgrounds of Canadiancitizens on the premise that a variety of racial, cultural, religious, and linguistic differences make Canada a much stronger country. In other words, as a "mosaic of cultures," Canada is unified by the continuing diversity of its citizens.

In the twenty years since, however, the proportion of Canadian residents of non-European ancestry has more than tripled to over $10 \%$ of the population. The complex practice of multiculturalism is becoming an abrupt reality rather than an abstract philosophy. As a result, a 1992 Southam News poll found that $55 \%$ of Canadians say racial prejudice is rising, $44 \%$ believe that racism is a fairly serious problem, and $36 \%$ of the residents of Vancouver believe racial riots are likely to occur in their city (Lowrie; 1992, p. A1).

The British Library Advisory Council, Canadian Library Association, American Library Association, and IFLA have all issued advisory documents about serving a multicultural community. These documents generally acknowledge difficulties with stocking outdated materials containing stereotypical images, library staffing which does not reflect the linguistic and racial composition of the population, and providing adequate service to small ethnic populations (Library Advisory Council, 1976; Multicultural Services Interest Group, 1986; Reference \& Adult Services Division, 1990; IFLA, 1987). The responsibility of the public library to help eliminate racism has been explored in the professional literature: (Shah, 1984), (Price, 1990), (Talbot, 1990), (Schulte-Albert, 1984), (Mylopoulos, 1985).

When asked whether a conflict exists between the philosophy of intellectual freedom and the goal of multicultural harmony, both British and Canadian directors were of divided opinions (see graph 3), with Canadian directors in slightly less agreement than the British. Not all of the 26 assenting directors chose to comment and their remarks were not extensive, but they tended to focus on two major points:

1) multicultural harmony and intellectual freedom are essentially conflicting ideals $(n=16)$, and/or

2) censorship is central to certain cultures and religions. $(n=12)$.

Most directors who noted reason \#1 consider the two ideals of multicultural harmony and intellectual freedom to be very difficult to achieve without compromise because the ideals are not mutually supportive but are working at cross purposes. According to them, it is naive in the 1990s to think that publication of inflammatory material will not create divisiveness between various races, religions, and cultures.

On the one hand you're saying that people can hold and publicize opinions that are degrading to minorities and they have the right to say them, and on the other hand you' re trying to get the groups to see each other as equal in worth and value. (Can.)

Some also referred to dissension caused by the mission of the public library to provide access to historical materials pertaining to cultures and races. Problems occur when the library tries to promote positive images while outdated and possibly negative images remain in the collection. 
We are going forward with new roles for women, new representations of races; and these are in conflict with the previous representations. (U.K.)

According to J.S. Mill, truth is strengthened when it is continually compared to falsehood (Mill, 1974, p. 116) but many of these directors are convinced that destructive disharmony rather than enlightenment is more likely to occur if falsehood and negative images are allowed a podium. They are reluctant to let negative images of ethnic minorities appear in the marketplace because of the possible offense taken by groups and individuals and the subsequent disruption to society.

Directors who noted that censorship is not universally considered an evil referred to personal experiences with the beliefs or practices of certainracial, religious, or cultural groups. These showed that many groups in British and Canadian society do not embrace the ideals of free exchange of ideas, open debate, and freedom of choice for the individual, and as a consequence, conflicts occur. The period of the interviews (early 1991) explains a focus by the directors on Moslems, both fundamentalist and other, because of the example of The Satanic Verses. Many British directors were also critical of the restrictions placed on access to information and freedom of choice for women of certain ethnic groups.

Knowledge is power, and the males of some ethnic groups will fight to keep women ignorant. (U.K.)

In contrast to assenting directors, the 33 who disagree that a conflict exists between intellectual freedom and multicultural harmony commented extensively. They based their remarks on goals and ideals rather than current social situations or actual conflict experiences. Two major points emerged:

1) knowledge removes biases and therefore helps multicultural harmony $(n=20)$, and/or

2) censorship of information creates a false multicultural harmony ( $\mathrm{n}=18$ ).

The unrestricted flow of information, even information offensive to certain groups, is seen as crucial for breaking down prejudicial barriers. Education and the broadening of perspectives are advocated as the best substructures for social harmony while ignorance and illiteracy or aliteracy were said to foster conflict.

I think it is the way people bend information and misappropriate information that is a detriment to multicultural harmony rather than intellectual freedom itself. It would be very sad if one said that the only way one could have complete harmony is restricting one's ability to think or speak. Surely what we ought to be trying to achieve is for everyone to think and speak positively; and I think you do that by a process of discussion, debate, and education rather than by constraining people as to what they can think. (U.K.)

Many directors fear that a "false harmony" would result from curtailing all information which might be offensive to various racial, religious, and ethnic groups. They believe "true" multicultural harmony can come only with discussion of racial issues because conflicts are rooted in attitudes rather than in offensive statements.

Hatred goes much deeper than hearing something said about us that we object to. We can hate without hearing or even knowing other people, as shown by our centuries of slaughter. (Can.)

Setting restrictions on dialogue was said to be "papering over the problem" of poor relations between groups and "letting it smoulder." Letting people express their points of view, even though offense may be caused, allows others to prove the speakers' errors.

Directors who disagree that a conflict exists generally focused on the long term benefits of the free flow of information, using phrases such as "in the long run" and "for a better future."

There are hard ways to do things and there are easy ways to do things, and sometimes the hard way is more effective in the long term. (Can.)

Contrary to their Likert response denying a conflict, most of the dissenting directors appear to acknowledge that at best, an uneasy relationship exists between the two concepts even though they did not envision an actual power struggle. In this relationship, they do not see that curtailing intellectual freedom will enhance multicultural harmony; nor that forsaking the goal of multicultural harmony will guarantee intellectual freedom. Most of the horrible racial problems we are facing today, we are facing because of ignorance or suppression of information. Let's try intellectual freedom. We can't make it any worse. (Can.)

Those directors who disagree that a conflict exists between intellectual freedom and multicultural freedom are generally very optimistic (and perhaps idealistic) in their outlook. In contrast, most of those who agree there is a conflict, both British and Canadian, are deeply discouraged with the violence and intolerance in their respective countries and see offensive remarks as catalysts for further hatred and bloodshed.

\section{CONCLUSION}

Introducing students of librarianship and information science to the complex relationship between their chosen profession and intellectual freedom/censorship issues is a difficult task. Students' personal decisions about controversial material are strongly influenced by their emotional reactions to such material, and they have difficulty acknowledging that a different level of decision, a professional decision, is necessary in the information professions.

Acquainting students with intellectual freedom and censorship association documents and emphasizing the relevant aspects of ethics codes indicates the importance of these issues to the profession, and prompts students who advocate censorship to examine problems more closely. Presenting only the professional "ideal" is a disservice to students, however, and therefore legal limitations on freedom of expression must be 
Graph 1

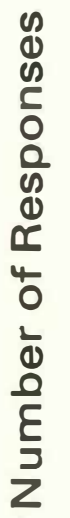

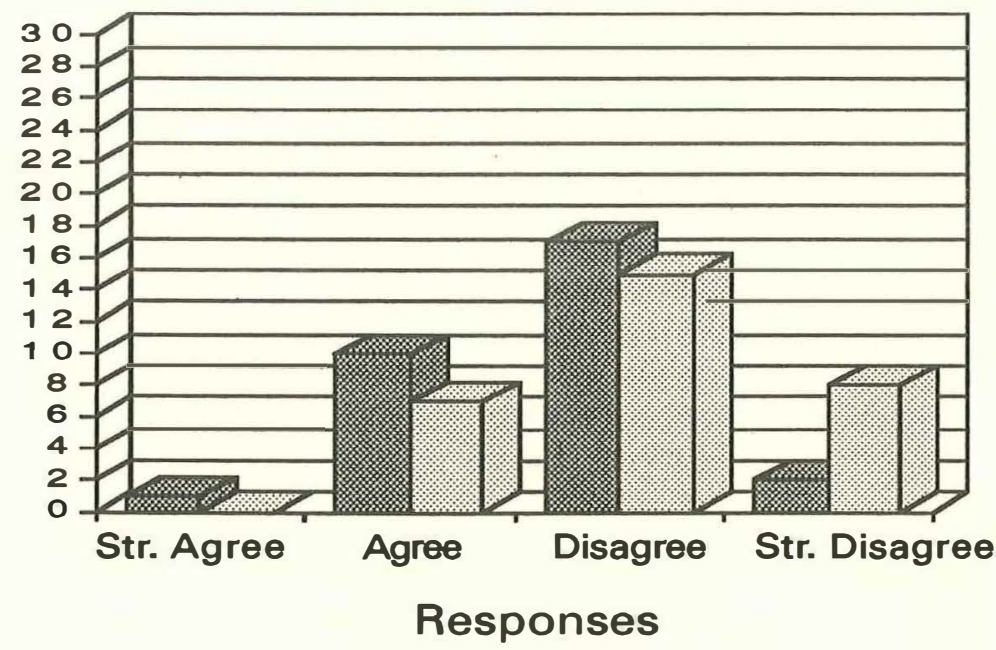

\section{STATEMENT:}

People should have the right to be protected from material which they personally consider to be offensive.

\section{Graph 2}

\section{STATEMENT:}

All ideas, no matter how repulsive, have a right to be heard

\section{Graph 3}

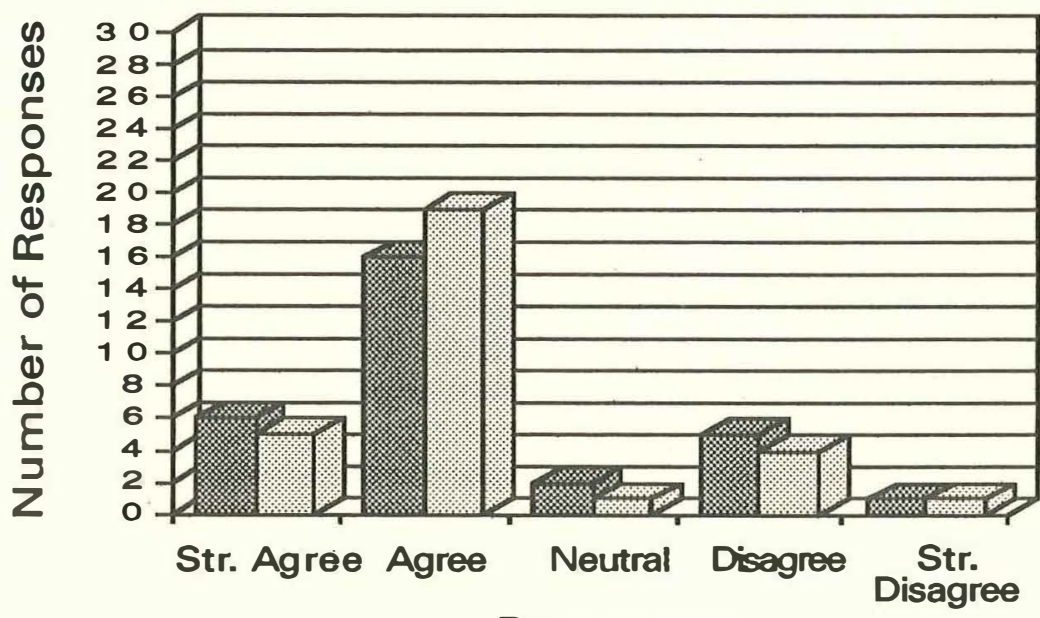

Responses

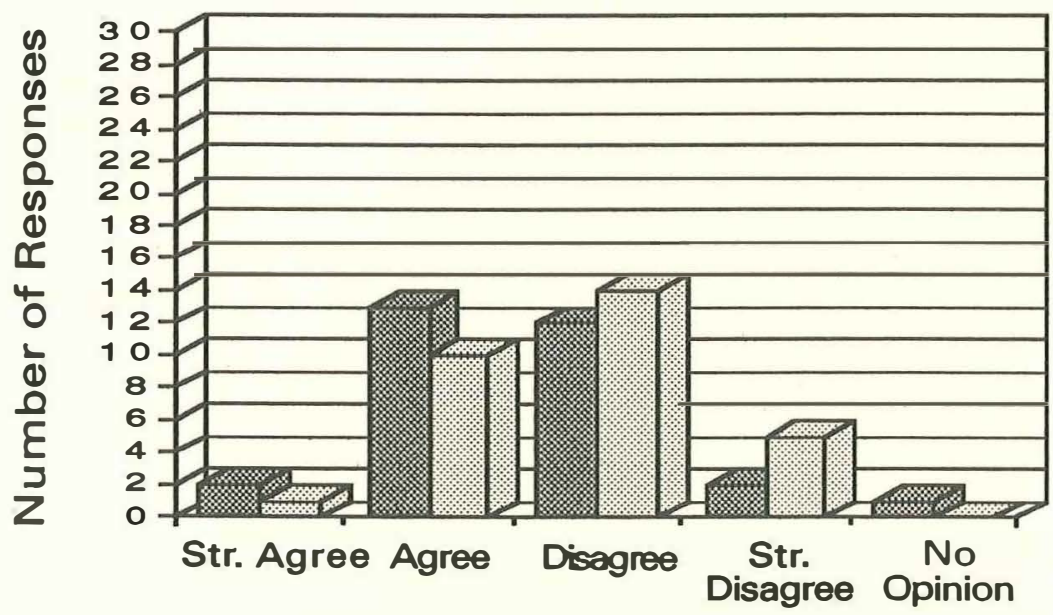

STATEMENT:

A conflict exists between the philosophy of intellectual freedom and the goal of multicultural harmony

Responses 
discussed. But perhaps most important in the instructional process is the presentation of dilemmas practicing librarians face when balancing personal and professional views, and the difficulties they encounter when making management decisions about controversial material. Using research-based data from practising librarians to construct case studies and discussion questions adds the element of reality needed to make students identify with the librarian and to prompt students to examine their own beliefs. This is crucial if students are not to reject intellectual freedom philosophies prescribed by their professional association because the philosophy does not immediately sit comfortably in their ethical framework. The library directors' responses in the three questions discussed indicate clearly that many are struggling with the complexities of intellectual freedom issues. Exploring the conflicting ethical values held by these directors reinforces for students the crucial concepts that no easy answers should be expected in this area and that the management of conflicting personal and professional ethical values within oneself is a common challenge for librarians.

\section{REFERENCES}

American Library Association. (1992). Intellectual freedom manual (4th edition). Chicago: ALA.

Bunting, Madeleine. (1990, April 18). Women force pornography off the shelf. The Guardian, p. 8.

Busha, Charles H. (1972). Freedom versus suppression and censorship: with a study of the attitudes of Midwestern public librarians and a bibliography of censorship. Littleton: Libraries Unlimited.

Byatt, A.S. (1988, Feb. 12-18). Obscenity and the arts - a symposium. Times Literary Supplement, pp. 159-61.

Canadian Library Association. (1985). Statement on intellectual freedom. Ottawa: CLA.

Child-pom law used for first time: Toronto artist (Eli Langer) charged. (1993, December 22). Globe \& Mail, p. A5

Constitution Act of 1982, Revised Statutes. Appendix 2 Part 12. (1985).

Curry, Ann. (1993). A comparison of the roles and attitudes of Canadian and British public library directors in dealing with intellectual freedom issues. Unpublished doctoral dissertation, University of Sheffield.

Ellis, Richard. (1994). Responsible practice: a review of CLA's Code of Ethics. Feliciter, 40(9), 40-49.

England, Claire St. Clere. (1974). The climate of censorship in Ontario: an investigation into attitudes toward intellectual freedom and the perceptual factors affecting the practice of censorship in public libraries serving medium-sized populations. Unpublished doctoral dissertation, University of Toronto.

Fennell, Tom. (1993, May 10). The centrefold war: do skin magazines violate human rights? Maclean's, 106, pp. 14, 16.

Hauptman, Robert. (1988). Ethical issues in librarianship. Phoenix: Oryx Press.
IFLA. Section of Library Services to Multicultural Populations. (1987). Multicultural communities: guidelines for library service. The Hague: International Federation of Library Associations.

Library Advisory Council (U.K.). (1976). Public Library Service for a Multi-cultural Society. Report produced by a joint party of the Advisory Council and the Community Relations Commission. N.p.

Library Association. (1986). Guidance notes on the Code of Professional Conduct. London: Library Association.

Library Association. (1987). Yearbook 1987. London: Library Association.

Lowrie, Wayne. (1992, June 2). Canadians fear racism on the rise. The Vancouver Sun, p. Al.

Mendus, Susan. (1990, Oct.). Legal rights can threaten freedoms. Index on Censorship, 19, pp. 11-12.

Mill, John Stuart. (1974). On Liberty. Harmondsworth: Penguin Books.

Milton, John. (1951). Areopagitica. Northbrook, Illinois: AHM Pub. Co.

Multicultural Services Interest Group. (1986). Guidelines for Multicultural Library Services in Canadian Public Libraries. Ottawa: Canadian Library Association.

Mylopoulos, Chryss. (1985). Trends in multicultural programming. Canadian Library Journal, 42, 23-25.

Neill, S.D. (1988). Censorship: a clash of values. Canadian Library Journal, 45, 35-39.

Neville, Richard. (1990, Sept./Oct.). Enough already! How far is too far when it comes to freedom of expression? Utne Reader, pp. 100-105.

Price, Neville. (1990, May). Cultural differences and library services. Library Association Record, pp. 377-78.

R. v. Butler. 2 Canada Supreme Court WWR 577 (1992).

Reference \& Adult Services Division (ALA). (1990). Guidelines for multilingual materials collection and development and library services. $R Q, 30(2), 268-271$.

Right to Offend. (1993, April 8). The Globe and Mail, p. A14.

Schulte-Albert, Hans G. (1984, June). Public library services to ethno-cultural minorities. Canadian Library Journal, 41, 115-120.

Shah, Aruna. (1984, Jan.). How to meet the ethnic need. Library Association Record, pp. 15-16.

Swan, John, \& Peattie, Noel. (1989). The freedom to lie. Jefferson, N.C.: McFarland.

Talbot, Christine. (1990, July). What is a multicultural library service? Library Association Record, pp. 501-503.

Vincent, Isabel. (1990, Sept. 25). 'Arts trial of the century' opens in Cincinnati. The Globe and Mail, p. A13.

Woodward, Diana. (1990). A framework for deciding issues in ethics. Library Trends, 39(1 \& 2), 8-17.

Dr. Ann Curry is an Assistant Professor for the School of Library, Archival, and Information Studies at The University of British Columbia, Vancouver, B.C. 